\title{
SYNTHESIS AND STUDY ON MAGNETIC RESONANCE IMAGING PERFORMANCE OF GD(III)-DTPA- BISBENZOTHIAZOL HYDRAZIDE
}

\author{
FU-XIAN WAN*, TIAN-KAI ZHANG, YING LI, CHANG-CHENG LI, LIN JIANG* \\ College of Chemistry and Material Science, Shan Dong Agricultural University, Taian 271018, People's Republic of China
}

\begin{abstract}
In this paper, 2-hydrazino-6-methoxy-1,3-benzothiazole was introduced into diethylenetriamine pentaacetic ( DTPA) by acylation reaction. The corresponding non-ion Gd(III) complex holding promise of a single molecule magnetic resonance imaging (MRI) contrast agent was obtained by treating this ligand with $\mathrm{GdCl}_{3} \cdot 6 \mathrm{H}_{2} \mathrm{O}$. The efficacy of the contrast agent was assessed by measuring the longitudinal relaxivity $\left(r_{1}\right)$, the $r_{1}$ of Gd(III)-DTPA-bisbenzothiazole hydrazide was up to $6.44 \mathrm{mM}^{-1} \cdot \mathrm{s}^{-1}$, which was 1.8 times higher than that of the analogous MRI contrast agent Gd(III)-DTPA $\left(r_{1}=3.64 \mathrm{mM}^{-1} \cdot \mathrm{s}^{-1}\right)$ in commercial use. In addition, in vitro MR images on a $0.5 \mathrm{~T}$ magnetic field exhibited a remarkable enhancement of signal contrast for Gd(III)-DTPA-bisbenzothiazole hydrazide than Gd(III)-DTPA. These results demonstrate that this non-ion Gd(III) complex acts as a potentially MRI contrast agent.
\end{abstract}

Keywords: MRI contrast agent; benzothiazole; DTPA derivative; gadolinium complex; relaxivity

\section{INTRODUCTION}

Over forty years later, magnetic resonance imaging (MRI) has become one of the most powerful tool in preclinical research and in the clinical diagnosis of various diseases around the word, due to its especially advantageous: high spatial $(<0.1 \mathrm{~mm})$ and temporal resolutions, 3-dimensional anatomical images, non-invasive (lack of ionizing radiation), deep tissue penetration and excellent soft tissue contrast and multiple contrast mechanisms ${ }^{1-3}$. In MRI, image contrast can be generated by differences in tissue water content, water relaxation times, flow, or diffusion ${ }^{4}$. Unfortunately the image contrast is often insufficient for diagnostic purposes. Contrast can be enhanced through the addition of an exogenous MRI contrast agents(CAs) to increase the relaxation rates of water protons in tissue in which the agent accumulates. Most commonly, this is a paramagnetic chelate that shortens the relaxation times of water molecules it encounters ${ }^{5-6}$. At present, the clinical utility of MRI icontrast agents is well established. Annually, at our medical institutions more than $50 \%$ of MRI scans were aided by contrast agents to diagnose disease ${ }^{7}$. Therefore, many research groups around the world have been studying MRI contrast agents. To date, more than nine types of the ligand of paramagnetic metal ionchelate complexes have been approved by Food and Drug Administration (FDA) for clinical application. A vast body of literature exists describing ligands for $\mathrm{Gd}(\mathrm{III})$, and the majority are polyaminopolycarboxylate ligands, like Gd-DTPA (DTPA=diethylenetriamine pentaacetic acid), Gd-DOTA (DOTA =1,4,7,10-tetraazacyclododecane-1,4,7,10-tetraacetic acid), Gd(HPDO3A) (HP-DO3A=10-(2-hydroxypropyl)-1,4,7,10-tetra-azacyclododecane1,4,7-triacetic acid), etc ${ }^{8-10}$.

However, most contrast agents have non-specific extracellular distribution and the disadvantages of low relaxivity, low tissue specificity, and rapid clearance. Moreover, most of the MRI contrast agents suffer low $T_{1}$ relaxivity, which is still far from expectation for highly sensitive MRI. These drawbacks have hindered the further development of MRI as a diagnostic tool ${ }^{11}$. Therefore, an ideal MRI contrast agent should be designed as the tissue or organ-targeting materials with high relaxivity, low toxicity and side effects, suitable long intravascular duration and excretion time, and high contrast enhancement with low dose, in vivo, all coupled to low overall $\operatorname{cost}^{12}$. More recently, by conjugation with a targeting moiety, low molecular weight gadolinium chelates provide strategy for new generation of tumor targeting contrast agent ${ }^{13-14}$.

Benzothiazole and its derivatives have been extensively investigated due to the high biological activity such as antimicrobial, anti-inflammatory and anticancer activity ${ }^{15-17}$. Based on the previous work, a great deal of research groups devoted to develop various benzothiazole derivatives with high antitumor activity in the past two decades. Gratifying results have been achieved in this area, conjugates of benzothiazoles with 1,4,7,10-tetraazacyclododecane-1,4,7tristert-butyl acetate (DO3A) have been employed as multimodal imaging probes such as magnetic resonance imaging (MRI)/optical and MRI/SPECT 18-19.

The above observations prompted us to design and synthesize a new gadolinium complex incorporating benzothiazole unit by the straightforward and efficient reaction of the bicyclic anhydride of diethylenetraiaminepentaacetic acid (DTPAA) with 2-hydrazino-6-methoxy-1,3-benzothiazole (3) (Scheme
1). The longitudinal relaxation time $\left(T_{1}\right)$ was measured, and spin-lattice relaxivity values $\left(r_{1}\right)$ of this $\mathrm{Gd}(\mathrm{III})$ complex was higher than that of Magnivest (Gd(III)-DTPA). In vitro MR images on a $0.5 \mathrm{~T}$ magnetic field exhibited that proton signal intensity increased with $\mathrm{Gd}(\mathrm{III})$ complex concentration and a remarkable enhancement of signal contrast for Gd(III)-DTPA-bisbenzothiazole hydrazide than Gd(III)-DTPA. Water-solubility tests showed that the solubility of the Gd(III)-L complex in water is largely and up to $0.8 \mathrm{~g} \mathrm{~mL}^{-1}$ at room temperature. These results showed that the complex is a prospective magnetic resonance imaging agent.

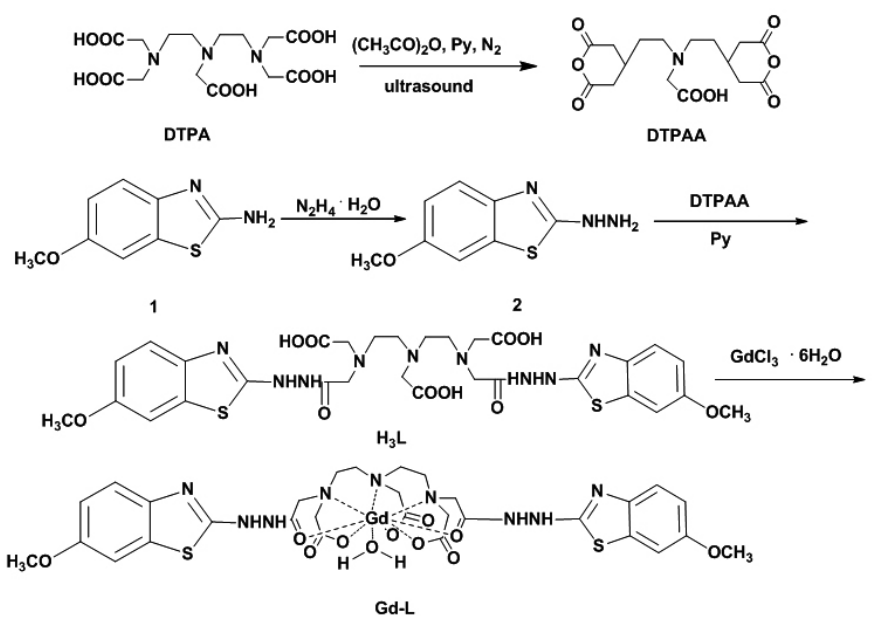

Scheme 1. Synthesis of ligand $\left(\mathrm{H}_{3} \mathrm{~L}\right)$ and complex(Gd(III)-L)

\section{EXPERIMENTAL}

\section{GENERAL}

Melting points were determined on a digital apparatus and are uncorrected. TLC analysis was performed on glass sheets coated with Merck silica gel 60 $\mathrm{F}_{254}$. Compounds were visualized by $\mathrm{I}_{2}$ steam or Uv-vis. ${ }^{1} \mathrm{H}-\mathrm{NMR}$ spectra were recorded on Bruker AV-400 spectrometers respectively. Chemical shifts $(\delta)$ were reported in parts per million from internal standard tetramethylsilane (TMS). Coupling constants $(J)$ were measured in Hertz. Multiplicity was reported as follows: $s$ (singlet), $d$ (doublet), $t$ (triplet), $m$ (multiplet) and combination of these signals. Column chromatographies were performed on silica gel 60 (200-300 mesh). IR spectrometry recorded with a Nicolet 380 FT-IR. Elemental analyses were determined on a Vario EL III(Elementar), Mass spectra were obtained on a Angilent6110 (Angilent Technologies, USA). The solvent longitudinal relaxation time $\left(T_{1}\right)$ for gadolinium complexes in distilled water was determined by a standard inversion-recovery sequence on the MicroMR imaging $\&$ analyzing system at $32{ }^{\circ} \mathrm{C}$ and $0.5 \mathrm{~T}$ ( Niumag Technology Co., Ltd., Suzhou, China ). MARS5 microwave digestion system. 
RT1001-RT1002 ultarsonic cleaning machine.

All reagents and solvents were analytical grade from commercial suppliers and used without further treatments unless otherwise stated. Reactions were carried out under $\mathrm{N}_{2}$ atmosphere, unless otherwise noted.

\section{SYNTHESES}

Synthesis of 2-hydrazino-6-methoxy-1,3-benzothiazole (2)

Concentrated hydrochloric acid $(8.6 \mathrm{~mL}, 36 \%, 0.1 \mathrm{~mol})$ was added drop wise with stirring to hydrazine hydrate $(11.5 \mathrm{~mL}, 85 \%, 0.2 \mathrm{M})$ at $0{ }^{\circ} \mathrm{C}$ followed by ethylene glycol $(30 \mathrm{~mL})$, there after 2-amino-6-methoxy-1,3-benzothiazole (1) $(9 \mathrm{~g}, 0.05 \mathrm{~mol})$ was added in portions and the resultant mixture was refluxed for $12 \mathrm{~h}$ and cooled at room temperature. The reaction progress was monitored by TLC using toluene:ethylacetate ( $v: v=75: 25)$ as mobile phase. The reaction mixture was filtered and resulting precipitate was washed with distilled water, then recrystallized from ethanol to give $\mathbf{2}$ as a reddish brown solid. Yield: $6.73 \mathrm{~g}$ (69 \%); mp 176-177.5 ${ }^{\circ} \mathrm{C}$. FT-IR (KBr pellet): 3200-3450 (-NHNH $), 1628$ $(\mathrm{C}=\mathrm{N}), 1448$ (thiazole) $\mathrm{cm}^{-1} ;{ }^{1} \mathrm{H}$ NMR $\left(400 \mathrm{MHz}, \mathrm{CDCl}_{3}, \delta / \mathrm{ppm}\right): 1.24$ (brs, $1 \mathrm{H}, \mathrm{NH}$, disappeared on $\mathrm{D}_{2} \mathrm{O}$ exchange), $3.83\left(\mathrm{~s}, 3 \mathrm{H},-\mathrm{OCH}_{3}\right), 4.22$ (brs, 2 $\mathrm{H}, \mathrm{NH}_{2}$, disappeared on $\mathrm{D}_{2} \mathrm{O}$ exchange), $6.92\left(\mathrm{dd}, J^{3}=8.8 \mathrm{~Hz}, J^{4}=2.4 \mathrm{~Hz}, 1 \mathrm{H}\right)$, 7.19 (d, $\left.J^{4}=2.4 \mathrm{~Hz}, 1 \mathrm{H}\right), 7.44\left(\mathrm{~d}, J^{3}=8.8 \mathrm{~Hz}, 1 \mathrm{H}\right)$. Anal. Calcd. for $\mathrm{C}_{8} \mathrm{H}_{9} \mathrm{~N}_{3} \mathrm{OS}$ $\left(w_{\mathrm{B}} / \%\right): \mathrm{C}, 49.21 ; \mathrm{H}, 4.65 ; \mathrm{N}, 21.52$; Found: $\mathrm{C}, 49.25 ; \mathrm{H}, 4.62 ; \mathrm{N}, 21.48$.

Synthesis of

diethylenetriamine-N,N"-bi(acetyl-6-methoxy-1,3-benzothiazole-2hydrazino) -N,N',N"-Triacetic acid (DTPA-bisbenzothiazole Hydrazide) $\left(\mathbf{H}_{3} \mathbf{L}\right)$

DTPA dianhydride (1.428 g, $4.0 \mathrm{mmol})$ and 2-hydrazino-6-methoxy-1,3benzothiazole (2) (1.56 g, $8.0 \mathrm{mmol})$ were dissolved in $20 \mathrm{~mL}$ dry pyridine and stirred at $60{ }^{\circ} \mathrm{C}$ for $4 \mathrm{~h}$ under $\mathrm{N}_{2}$ atmosphere. After removal of the solvent, the solid residue was washed with iced water and dried in vacuo, then recrystallized from methanol:water $(v: v=3: 1)$ to give $\mathrm{H}_{3} \mathrm{~L}$ as a yellowish solid. Yield: $2.4 \mathrm{~g}(80 \%)$; $\mathrm{mp} 138-140^{\circ} \mathrm{C}$. FT-IR (KBr pellet): 3446,3045 , $2964,2883,1729,1650,1473,1385,1230,1133,619,544 \mathrm{~cm}^{-1} ;{ }^{1} \mathrm{H}$ NMR $(400$ MHz, DMSO- $\left.d_{6}, \boldsymbol{\delta} / \mathrm{ppm}\right): 2.73\left(\mathrm{t}, 4 \mathrm{H}, 2 \times \mathrm{N}-\mathrm{CH}_{2}\right), 2.89\left(\mathrm{t}, 4 \mathrm{H}, 2 \times \mathrm{N}-\mathrm{CH}_{2}\right)$ $2.95(\mathrm{~s}, 4 \mathrm{H}, 2 \times \mathrm{N}-\mathrm{CH}-\mathrm{CO}-\mathrm{NH}) 3.27\left(\mathrm{~s}, 4 \mathrm{H}, 2 \times \mathrm{N}-\mathrm{CH}_{2}-\mathrm{COOH}\right), 3.42(\mathrm{~s}, 2 \mathrm{H}$, $\mathrm{N}-\mathrm{CH}_{2}-\mathrm{COOH}$ ), $3.74\left(\mathrm{~s}, 6 \mathrm{H}, 2 \times \mathrm{O}_{-} \mathrm{CH}_{3}\right), 4.12$ (brs, $2 \mathrm{H}, \mathrm{NH}$ disappeared on D O exchange), 6.87-6.84 (dd, $2 \mathrm{H}, \mathrm{Ar}-\mathrm{H}), 7.34$ (m, $2 \mathrm{H}, \mathrm{Ar}-\mathrm{H}), 7.36$ (m, $2 \mathrm{H}$, Ar-H), 7.95 (s, 2 H, -CONH-).

Anal. Calcd. for $\mathrm{C}_{30} \mathrm{H}_{37} \mathrm{~N}_{9} \mathrm{O}_{10} \mathrm{~S} \cdot \mathrm{CH}_{3} \mathrm{CH}_{2} \mathrm{OH} \cdot \mathrm{H}_{2} \mathrm{O}\left(w_{\mathrm{B}} / \%\right)$ : C, 47.34; $\mathrm{H}$, 5.59; $\mathrm{N}, 15.53$. found $\mathrm{C}, 47.43 ; \mathrm{H}, 5.47 ; \mathrm{N}, 15.37$. ES-API-MS(positive mode) $\mathrm{m} / \mathrm{z}[\mathrm{M}+\mathrm{H}]^{+}$Calcd. $748.21 \mathrm{Da}$; Obsd. 748.3 Da and $[\mathrm{M}+2 \mathrm{H}]^{2+}$ Calcd. $374.6 \mathrm{Da}$ Obsd. $374.7 \mathrm{Da}$

Synthesis of Gd(III)- DTPA-bisbenzothiazole Hydrazide(Gd(III)-L)

Diethylenetriamine-N,N"-bi(acetyl-6-methoxy-1, 3-benzothiazole-2hydrazino) - N,N',N"-Triacetic acid (DTPA-bisbenzothiazole Hydrazide) $\left(\mathrm{H}_{3} \mathrm{~L}\right)(0.748 \mathrm{~g}, 1.0 \mathrm{mmol})$ was dissolved in water $(15 \mathrm{~mL})$ to which was added gadolinium(III) chloride hexahydrate $(0.37 \mathrm{~g}, 1.0 \mathrm{mmol})$. The mixture was stirred at room temperature for $24 \mathrm{~h}$, during which time $\mathrm{pH}$ of the solution was periodically adjusted to 7.0-7.5 with $\mathrm{NaOH}(1.0 \mathrm{M})$. Until no free gadolinium ions was detected by the xylenol orange test, water was removed by evaporation, and the remaining oily product was taken up in a minimum amount of water $(\sim 5$ $\mathrm{mL}$ ) to be added dropwise to acetone for precipitation. The white precipitate thus formed was removed by filtration, washed with acetone, and dried under vacuum to yield an off-white solid. Yield: $0.874 \mathrm{~g}(95 \%) ; \mathrm{mp}>250^{\circ} \mathrm{C}$. FT-IR ( $\mathrm{KBr}$ pellet): $3434,2975,2883,1610,1464,1406,1386,1232,1125,1092$, $545,519 \mathrm{~cm}^{-1}$; Anal. calcd for $\mathrm{C}_{30} \mathrm{H}_{42} \mathrm{GdN}_{9} \mathrm{NaO}_{14} \mathrm{~S}_{2}\left(w_{\mathrm{B}} / \%\right)$ : C, 36.14; $\mathrm{H}, 4.25$; $\mathrm{N}, 12.64$. found $\mathrm{C}, 36.43 ; \mathrm{H}, 4.17 ; \mathrm{N}, 12.57$.

\section{Relaxation Measurements}

In this experiment, the concentration of gadolinium ion $\left[\mathrm{Gd}^{3+}\right]$ was measured by an ICP Atomscan-2000 spectrometer. The solvent longitudinal relaxation time $\left(T_{1}\right)$ for gadolinium complex was carried out on a solution of gadolinium complex in distilled water at concentrations ranging from 0.0 to 2.0 $\mathrm{mM}(0.4,0.8,1.2,1.6$ and $2.0 \mathrm{mM})$ were measured by a standard inversionrecovery sequence on the MicroMR imaging \& analyzing system at $32{ }^{\circ} \mathrm{C}$ and $0.5 \mathrm{~T}$ (Niumag Technology Co., Ltd., Suzhou, China). Thus the relaxivity $r$, for gadolinium complex in distilled water can be calculated. This Gd(III)-complex was compared with Magnevist (Gd(III)-DTPA) at the same condition.

\section{$T_{1}$-Weight imaging in vitro}

In vitro imaging effect of Gd(III)-DTPA-bisbenzothiazole hydrazide is visualized by FLASH images in phantoms. Multislice spin echo (MSE) sequence $(\mathrm{TR}=100 \mathrm{~ms}$, $\mathrm{TE}=12.5 \mathrm{~ms}$, NS=32, Slice thickness $=3.0 \mathrm{~mm})$ on the MR23-060H-I imaging \& analyzing system( $0.5 \mathrm{~T})$ was employed for the acquisition of the in vitro imaging.

\section{RESULTS AND DISCUSSION}

As mentioned previously, because of the favorable pharmacological properties of benzothiazole compounds, we have produced the corresponding DTPA analogues containing benzothiazole. The synthetic scheme of ligand (DTPA-bisbenzothiazole hydrazide, $\mathrm{H}_{3} \mathrm{~L}$ ) is shown in Scheme 1.

The structure of ligand was characterized by FT-IR, ES-API-MS, ${ }^{1} \mathrm{H}$ NMR and elemental analysis. ${ }^{1} \mathrm{H}$ NMR, FT-IR were conformed with the structure of diethylenetriamine-N,N"-bis(acetyl-6-methoxy-1, 3-benzothiazole-2hydrazino) - N, $\mathrm{N}^{\prime}, \mathrm{N}^{\prime}$--triacetic acid (DTPA-bisbenzothiazole hydrazide, $\mathrm{H}_{3} \mathrm{~L}$ ). The ${ }^{1} \mathrm{H}$ NMR spectrum of the ligand $\left(\mathrm{H}_{3} \mathrm{~L}\right)$ was shown in Fig. S2. The ${ }^{1} \mathrm{H}$ NMR spectra showed the characteristic peaks of $\mathrm{NCH}_{2} \mathrm{COOH}$ groups of DTPA structure and benzyl groups of benzothiazole structure, indicating that DTPA was covalently bound to benzothiazole. The ES-API-MS spectra(Fig. S3) revealed that the molecular ion peaks were in accordance with the given structure of it. ES-API-MS(positive mode): $\mathrm{m} / \mathrm{z}[\mathrm{M}+\mathrm{H}]^{+}$Calcd. $748.21 \mathrm{Da}$; Obsd. 748.3 Da.

The Gd(III)-L complex was prepared by reacting the ligand with stoichiometric amounts of the $\mathrm{GdCl}_{3} \cdot \mathbf{6} \mathrm{H}_{2} \mathrm{O}$ in high yield. Watersolubility tests showed that the solubility of the Gd(III)-L complex in water is largely and up to $0.8 \mathrm{~g} \mathrm{~mL}^{-1}$ at room temperature. According to reported method ${ }^{20}$ : Gd(III)-DTPA-bisbenzothiazole hydrazide was dissolved in distilled water at concentration of $10.0 \mathrm{mM}$, then the solution of Gd(III) complex was added into oxalic ion $\left(\mathrm{C}_{2} \mathrm{O}_{4}{ }^{2-}\right)$ and the molar amount 10 times than that of $\mathrm{Gd}(\mathrm{III})$ complex, the mixed solution was stand for 30 days under room temperature. After careful observation, the mixed solution was keep clear and transparent. It illustrated that this $\mathrm{Gd}(\mathrm{III})$ complex is preliminarily stable in vitro.

In the FT-IR spectra of the ligand(Fig. 1a), strong and broad absorption peaks at $3446 \mathrm{~cm}^{-1}$ were attributed to $v \mathrm{OH}$ and $v \mathrm{NH}$. The peaks at $1725 \mathrm{~cm}^{-1}$ (A) and $1660 \mathrm{~cm}^{-1}(\mathrm{~B})$, were attributed to $v \mathrm{COOH}$ and $v \mathrm{CONH}-$, respectively. For Gd(III)-L complex(Fig. 1b), the band (A) disappeared in the complex, showing that the carboxyl proton dissociates and the oxygen atom was coordinated to metal. The band (B) was shifted to $1610 \mathrm{~cm}^{-1}$, suggesting that the oxygen atom of the amide is coordinated to metal ${ }^{21}$. The ligand provided three nitrogen atoms, five carboxyl oxygen atoms bonding to metal.

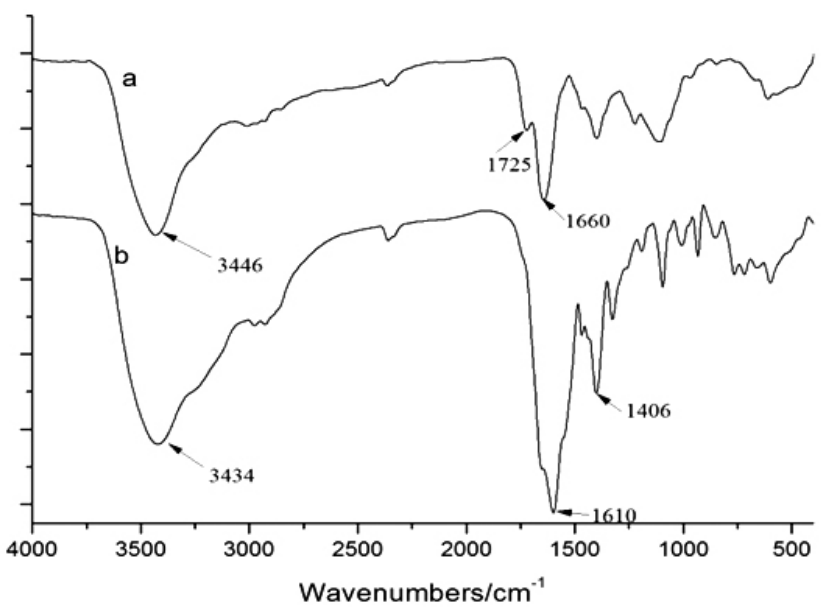

Fig. 1 FT-IR spectrum of $\mathrm{H}_{3} \mathrm{~L}(\mathrm{a})$ and $\mathrm{Gd}(\mathrm{III})-\mathrm{L}$ complex (b)

The effects of paramagnetic ions on the $T$, relaxation nuclear spins were first formulated by Bloembergen and Solomon and subsequently extended by several authors ${ }^{22-23}$. On the basis of this theory, the longitudinal relaxation time $T_{1}$ in the presence of Gd complex is given by Eq. (1):

$$
1 / T_{1, \mathrm{obsd}}=1 / T_{1, \mathrm{~d}}+r_{1}[\mathrm{M}]
$$

where $\left(1 / T_{1}\right)_{\text {obsd }}$ is the observed solvent relaxation rate in the presence of a paramagnetic species, $\left(1 / T_{1}\right)_{d}$ is the solvent relaxation rate in the absence of a paramagnetic species, $[\mathrm{M}]$ denotes the concentration of gadolinium ion in the measured solution, and $r_{1}$ is the relaxivity of the agent in a unit of $\mathrm{mM}^{-1} \mathrm{~s}^{-1}$, which is the most important parameter in evaluating a contrast agent and was calculated from the slope of the plots of $\left(1 / T_{1}\right)_{\text {obsd }}$ versus the Gd concentrations. Fig. 2 illustrates that the relaxivity of gadolinium complex produced in our present work was $6.44 \mathrm{mM}^{-1} \cdot \mathrm{s}^{-1}$, which was 1.8 times higher than that of the 
analogous MRI contrast agent Gd(III)-DTPA $\left(r_{1}=3.64 \mathrm{mM}^{-1} \cdot \mathrm{s}^{-1}\right)$ in commercial use at the same condition. Possible explanations for increased relaxivity, relative to clinical contrast agent Gd(III)-DTPA, include: (a) increasing the molecule size by introducing an aromatic group causes a decrease in rotational correlation rate(relatively long rotational correlation time); (b) an increase in the number of outer sphere coordinated water molecules via hydrogen bonds to the nitrogen atoms of the thiarizonaole groups; (c) hydrophilic hydrazide group may be able to transmit water molecule from outer-sphere to the inner-sphere easily.

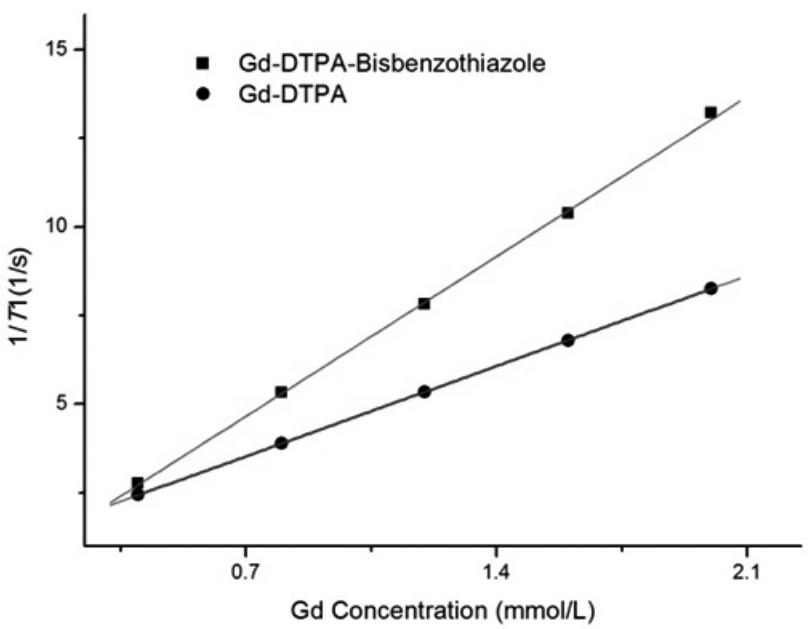

Fig. 2 Plots of $1 / T_{1}$ vs the Gd concentrations of Gd(III)-L complex as well as Gd-DTPA in water solution

The Fig. 3 showed in vitro MR images prepared by Gd(III)-DTPA(b) and Gd(III)-L (a) solutions in phantoms. It was seen that proton signal intensity increased with $\mathrm{Gd}(\mathrm{III})$ complex concentration. Besides, the imaging effect of Gd(III)-L was superior to that of Gd(III)-DTPA in the same condition.

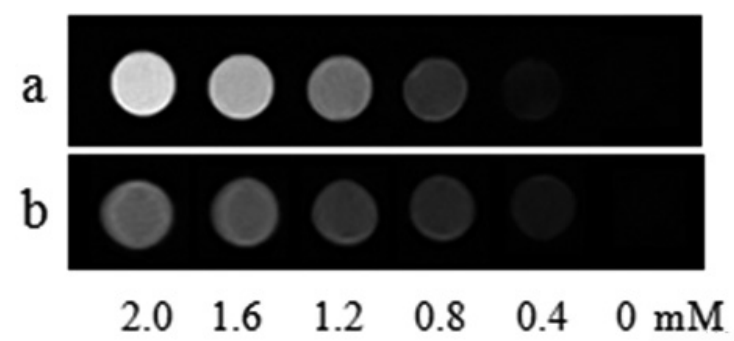

Fig. $3 T_{1}$-weighted phantom MR images for Gd(III)-L complex (a) and Gd-DTPA(b) with a concentration of $0-2.0 \mathrm{mM}$

\section{CONCLUSIONS}

In summary, We have successfully synthesized a new gadolinium complex(Gd(III)-L complex by a simple and efficient reaction. The longitudinal relativity $\left(r_{1}\right)$ of this $\mathrm{Gd}(\mathrm{III})-\mathrm{L}$ complex is higher than that of Gd(III)-DTPA, and the in vitro imaging effect of Gd(III)-L was superior to that of $\mathrm{Gd}(\mathrm{III})-$ DTPA in the same condition, which makes it possible to reduce the risk of the toxicity by lowering the dose of Gd(III) chelates. Thus Gd(III)-L might be considered as a potential MRI contrast agent.

\section{ACKNOWLEGEMENTS}

This project was supported by Shandong Province Science and Technology Development Plan (No. 2013GZX20109) and Shandong Province Natural Science Foundation (No. ZR2014BM030).

\section{REFERENCES}

1. P.C. Lauterbur, Nat. 242, 190, (1973).

2. J. Lee, J. E. Burdette, K.W. MacRenaris, D. Mustafi, T.K. Woodruff, T. Meade, J. Chem. Biol. 14, 824, (2007).

3. L. Frullano, P. Caravan, Curr. Org. Synth. 8, 535, (2011).

4. K.M. Payne, M. Wood, Bioconjugate Chem. 26, 338, (2015).

5. P. Caravan, J.J. Ellison, T.J. McMurry, R.B. Lauffer, Chem. Rev. 99, 2293, (1999).

6. Y. Huang, B. Cao, X. Yang, Q. Zhang, X. Han, Z. Guo, Magn.Reson.Imag. 31, 604, (2013).

7. E. Boros, E. M. Gale, P. Caravan, Dalton Trans. 44, 4804, (2015).

8. K. Yu, Y. Hamdan, F. Wan, Y. Li, K. Huang, J. Zhou, Aust. J. Chem. 60, 218, (2007)

9. C.Q. Tu, E.A. Osborne, A.Y. Louie, Tetrahedron 65, 1241, (2009).

10. F. Wan, K.Yu, Chin. J. Org. Chem. 34, 613, (2014).

11. X. Zhou, L. Yang, G. Yan, W. Xu, C. Zhou, Q. Zhang, L. Li, F. Liu, J. Guo, Q. Zhao, J. Rare. Earth. 30, 884, (2012).

12. D. Zhang, X. Zhang, Z. Lin, H. Zhang, Y. Chen, S. He, Inorg. Chem. Comm. 40, 66, (2014).

13. C. Salt, A.J. Lennox, M. Takagaki, J.A. Maguire, N.S. Hosmane, Russ Chem. Bull. Int. Ed. 53, 1871, (2004).

14. C.A. Mathis, Y. Wang, D.P. Holt, G.F. Huang, M.L. Debnath, W.E. Klunk, J. Med. Chem. 46, 2740, (2003).

15. T.D. Bradshaw, A.D. Westwell, Curr. Med. Chem. 11, 1009, (2004)

16. X. Chen, P. Yu, L. Zhang, B. Liu, Bioorg. Med. Chem. Lett. 18, 1442 , (2008).

17. N. Saini, R. Varshney, A.K. Tiwari, A. Kaul, M. Allard, M.P. Ishar, A.K. Mishra, Dalton Trans. 42, 4994, (2013).

18. E.L. Crossley, J. B. Aitken, S. Vogt, H.H. Harris, L.M. Rendina, Angew. Chem. Int. Ed. Engl. 49, 1231, (2010).

19. T. Yamamoto, K. Nakai, A. Matsumura, Cancer.Lett. 262,143, (2008).

20. A.D. Sherry, R.D. Brown, C. F.G.C. Geraldes, S.H. Koenig, K-T. Kuan, M. Spiller, Inorg. Chem. 28, 620, (1989).

21. H.-A. Tang, Y. Sheng, R.-D. Yang, Inorg. Chem. Comm. 6, 1213, (2003).

22. I. Solomon, Phys. Rev. 99, 559, (1955).

23. N. Bloembergen, E.M. Purcell, R.V. Pound, Phys. Rev. 73, 679, (1948) 